\title{
BMJ Open What are the measures taken to prevent COVID-19 infection among healthcare workers? A retrospective study in a cluster of primary care clinics in Singapore
}

Peter Kirm Seng Moey (D) , ,2 Andrew Teck Wee Ang, ${ }^{1,2}$ Adrian Guan Liang Ee, ${ }^{1,2}$ David Chee Chin Ng (D) , ,,2 Mark Chung Wai Ng, ${ }^{1,2}$ Stephanie Swee Hong Teo, ${ }^{1}$ Ee Guan Tay, ${ }^{1,2}$ Ngiap Chuan Tan (i) ${ }^{1,2}$

To cite: Moey PKS, Ang ATW, Ee AGL, et al. What are the measures taken to prevent COVID-19 infection among healthcare workers? A retrospective study in a cluster of primary care clinics in Singapore. BMJ Open 2021;11:e049190. doi:10.1136/ bmjopen-2021-049190

- Prepublication history for this paper is available online. To view these files, please visit the journal online (http://dx.doi. org/10.1136/bmjopen-2021049190).

Received 20 January 2021 Accepted 28 May 2021

Check for updates

(c) Author(s) (or their employer(s)) 2021. Re-use permitted under CC BY-NC. No commercial re-use. See rights and permissions. Published by BMJ.

${ }^{1}$ SingHealth Polyclinics,

Singapore

${ }^{2}$ Family Medicine Academic Clinical Programme, SingHealth Duke-NUS, Singapore

Correspondence to Dr Peter Kirm Seng Moey; peter.moey.k.s@singhealth. com.sg

\section{ABSTRACT}

Objective To examine factors contributing to the low COVID-19 infectivity rate among healthcare workers in SingHealth Polyclinics (SHP), Singapore, from February to July 2020.

Design Retrospective description, analysis and discussion of the factors and their contribution.

Setting Single-institution study.

Methods We describe and discuss the healthcare policies, infrastructure, people and processes contributing to the low COVID-19 infectivity rate in SHP.

There were 1212 full-time and 198 contract staff. Of these, 171 SHP employees also supported the work in dormitories, isolation and community care facilities. During the review period, healthcare workers (HCWs) in SHP managed about 867076 patient attendances, including 63503 for upper respiratory tract infections, across its cluster of eight polyclinics. 29642 swabs for COVID-19 were performed in SHP, with 126 positive results. 395 swabs were carried out in the dormitories and 59 were positive. Despite the high exposure, only two SHP staff were infected with COVID-19. Both have recovered well. Results Provision of adequate personal protection equipment, zonal segregation of high-risk patients, reduction in physical patient visits, effective staff communication, implementation of self-declared temperature monitoring and the maintenance of sustainable workload and work hours of HCWs contributed to the mitigation of COVID-19 infection risk among our staff.

Conclusions Until the widespread uptake of safe and effective vaccines against COVID-19, these measures are important in protecting HCWs. They are also important when managing future pandemics of similar nature to COVID-19.

\section{INTRODUCTION}

COVID-19 infection was first reported in Singapore on 4 February 2020, spread to the first thousand local Asian population by 1 April 2020 and increased to 50000 by
Strengths and limitations of this study

- Details in the description of protective measures for healthcare workers may be used for reference by organisations when they design workflows to handle disease outbreaks with similar nature to COVID-19.

- Relevant data are provided for some measures, which can be used as reference.

- Retrospective and some data are not available.

Self-reporting of temperature by staff lacks verification and standardisation.

- A deductive approach was used in correlating the effectiveness of the measures.

26 July 2020. ${ }^{1}$ Most local acute respiratory infections are first seen in public or private primary care clinics. Those suspected of COVID-19 infection are referred from these clinics to the secondary and tertiary hospitals for further management. Primary care providers are thus susceptible to COVID-19 infections, being in the frontline interacting with suspected infected patients.

In Singapore, a total of 88 healthcare workers (HCWs) were diagnosed with COVID-19 infections as of 17 April 2020. ${ }^{3}$ In SingHealth Polyclinics (SHP), a large local primary healthcare organisation with over 1200 employees, only two HCWs were infected with COVID-19 (as of 30 November 2020) and both have fully recovered. Its HCWs managed about 867076 patient attendances (63503 for upper respiratory tract infections) across its cluster of eight primary care clinics (polyclinics) from February to July 2020.

In contrast, the WHO reported at least 22 073 HCWs infections worldwide as of 8 April $2020{ }^{4}$ In China, as of 24 February 2020, $1716(3.8 \%)$ of its infected 44672 patients 
were HCWs who worked in medical facilities, resulting in five deaths. ${ }^{5}$ In the USA, 9282 HCWs were infected with COVID-19 as of 9 April $2020 .^{6}$

\section{AIM}

The study aimed to describe, analyse and discuss the healthcare policies, infrastructure, people and processes in mitigating COVID-19 infectivity rate among HCWs in SHP, a Singapore primary healthcare organisation, from February to July 2020. We postulated that the combination of these measures in the organisation was effective in mitigating the risks of COVID-19 infection to HCWs.

\section{METHOD}

\section{Patient and public involvement}

No patient or public was involved in this study.

\section{Primary care sites, infrastructure and services}

Singapore has a dual public and private primary healthcare system. SHP is one of three local public primary care institutions. Its polyclinics are located in eastern Singapore, with central coordination at its headquarter. ${ }^{7}$ The infrastructure and layout of each polyclinic is different, from standalone buildings to tenants in community complexes. The clinic spaces range from 1739 to 8511 square metres.

SHP provides a comprehensive range of primary care services, on-site pharmacy as well as dental and allied health services in designated clinics. Each polyclinic healthcare team serves about 400-1200 multiethnic Asian patients daily during office hours from Mondays to Fridays and half a day on Saturdays.

SHP conducts medical undergraduate and postgraduate residency training in family medicine. The organisation also offers continuing professional education to doctors, nurses, pharmacists and internship to the respective undergraduates. Primary care research is also conducted in every polyclinic.
Healthcare policy and system during the COVID-19 outbreak Disease outbreak operational framework at the polyclinics

Singapore uses a colour-coded framework called Disease Outbreak Response System Condition (DORSCON) to reflect the outbreak situation. ${ }^{8}$ The 'green', 'yellow', 'orange' and 'red' colours indicate increasing severity of disease outbreak, with corresponding recommended action plans. DORSCON was switched from green to yellow on 22 January 2020, and subsequently to orange on 7 February 2020. A multiministerial government taskforce imposed a national lockdown termed 'circuit breaker' from 7 April to 2 June 2020 and was lifted partially on 19 June 2020. ${ }^{910}$

At the institution level, a multidisciplinary Disease Outbreak Task Force (DOTF) led by the chief executive officer was established. SHP has an existing framework for disease outbreaks, learning from severe acute respiratory syndrome (2002) and influenza A H1N1 (2010), enabling a rapid adaptation to measures required. Centred at the institution headquarter, DOTF organised weekly meetings with polyclinic directors and sent out regular advisories to the polyclinic management teams to implement measures.

\section{Reorganisation of medical and dental services}

During the circuit breaker, SHP services were reorganised into essential and non-essential services (table 1). Nonessential services were stopped during the circuit breaker, while essential services were scaled down where possible.

Each polyclinic's layout is reconfigured into 'red', 'yellow' and 'green' zones to accommodate patients segregated by their COVID-19 risk profiles (table 2). For smaller polyclinics, 'red' and 'yellow' zones may be located outside the premises, including installation of tents and rental of adjacent community facilities. The number of patients in each zone can be retrieved from the institution's information technology system. Swabs for COVID-19 were performed in 'yellow' zones based on prevailing criteria by Ministry of Health, Singapore.

Table 1 Reorganisation of primary care services in SHP

\begin{tabular}{|c|c|}
\hline Essential services & Non-essential services \\
\hline General medical consultation & Specialised services: musculoskeletal, memory and mental health services \\
\hline $\begin{array}{l}\text { Second-tier clinic for patients with complex } \\
\text { needs }\end{array}$ & $\begin{array}{l}\text { Ancillary service (advanced care planning, family planning, driving license renewal } \\
\text { and nursing home application) }\end{array}$ \\
\hline $\begin{array}{l}\text { Nurse-led services in non-communicable } \\
\text { diseases (NCDs) management and direct } \\
\text { observed therapy for tuberculosis }\end{array}$ & $\begin{array}{l}\text { Allied health services (dietetics, physiotherapy, podiatry, spirometry and medical } \\
\text { social support) }\end{array}$ \\
\hline Telesupport services (NCD) & Cancer screening (cervical and breast cancer) \\
\hline Nurse-led wound management & Screening for diabetic retinal and feet complication \\
\hline Dental: urgent and emergency cases & Dental: elective cases \\
\hline
\end{tabular}

SHP, SingHealth Polyclinics. 
Table 2 Recommended PPE attire at various zones in SHP

\begin{tabular}{|c|c|c|}
\hline Location & $\begin{array}{l}\text { Risk of COVID-19 } \\
\text { infection* }^{*}\end{array}$ & $\begin{array}{l}\text { Minimum PPE } \\
\text { requirement }\end{array}$ \\
\hline $\begin{array}{l}\text { Screening at } \\
\text { clinic entrance }\end{array}$ & Undifferentiated & $\begin{array}{l}\text { N95 mask, visor } \\
\text { or goggles (eye } \\
\text { protection) }\end{array}$ \\
\hline Green zone & $\begin{array}{l}\text { Low } \\
\text { (does not meet any } \\
\text { criteria for suspect }^{*} \text { ) }\end{array}$ & Surgical mask \\
\hline Yellow zone & $\begin{array}{l}\text { Medium } \\
\text { (meets only some } \\
\text { criteria for suspect }^{*} \text { ) }\end{array}$ & $\begin{array}{l}\text { N95 mask, gown, eye } \\
\text { protection gear and } \\
\text { gloves }\end{array}$ \\
\hline Red zone & $\begin{array}{l}\text { High } \\
\text { (fully meets criteria } \\
\text { for suspect }{ }^{\star} \text { ) }\end{array}$ & $\begin{array}{l}\text { N95 mask, gown, eye } \\
\text { protection gear and } \\
\text { gloves }\end{array}$ \\
\hline
\end{tabular}

${ }^{*}$ Based on prevailing national guidelines on criteria for COVID-19 suspect.

PPE, personal protection equipment; SHP, SingHealth Polyclinics.

Non-essential radiological services are suspended during the circuit breaker. When COVID-19 suspects require chest X-rays, they are masked and escorted to the in-house radiological facilities by staff in full PPE via dedicated lifts and pathways. The radiological premise is vacated of other patients. After attending to the COVID-19 suspects, the radiological equipment are sterilised before the next patient.

Dental services are restricted to urgent or emergency dental care. Patients are scheduled according to aerosol and non-aerosol generating procedures based on phone triage by dental staff. Aerosol-based procedures require higher level of infection control and are scheduled towards the end of the day.

Diagnosis and contact tracing of patients tested positive for COVID-19

COVID-19 suspects are swabbed for PCR tests. The results are known within 24-48 hours. The dedicated contacttracing team in each polyclinic team will commence contact tracing of those affirmed with COVID-19 infection. HCWs in contact with these infected patients are advised on strict personal surveillance and to take immediate sick leave when clinical signs and symptoms of infection emerged.

\section{Staff}

The composition and demographic profile of the 1212 SHP staff and 198 contract workers are shown in table 3. Key appointment holders in headquarter include clinician-leaders who manage patients at the polyclinics.

\section{Personal protection}

All staff don personal protection equipment (PPE) corresponding to the infection risk profiles of patients at the respective zones (table 3 ).

Mask fitting is performed for all staff to ensure adequate protection. Refitting is encouraged for staff with recent
Table 3 Staff demographic characteristics

Number of staff

number (\%)

SHP staff $(n=1212)$

Age (years)

$\begin{array}{lc}<40 & 638(52.6) \\ 40-65 & 523(43.2) \\ >65 & 51(4.2) \\ \text { Gender } & \\ \text { Male } & 190(15.7) \\ \text { Female } & 1022(84.3) \\ \text { Race } & \\ \text { Chinese } & 820(67.7) \\ \text { Malay } & 211(17.4) \\ \text { Indian } & 127(10.5) \\ \text { Others } & 54(4.5) \\ \text { Deployment } & \\ \text { Clinics only } & 1019(84.1) \\ \text { HQ only } & 171(14.1) \\ \text { HQ and clinics* } & 22(1.8)\end{array}$

Job categories

Doctor (including locums) 223 (18.4)

Nurse

$281(23.2)$

Dentist

$22(1.8)$

Dental staff

$29(2.4)$

In-house pharmacy staff

$166(13.7)$

Operations/administrative

464 (38.3)

Allied health (includes physiotherapists, podiatrists, dietitians and medical social workers)

\section{Contract staff $(\mathrm{n}=198)$}

$\begin{array}{lc}\text { Laboratory and radiology† } & 85(42.9) \\ \text { External contractors } \ddagger & 106(53.5) \\ \text { Retail pharmacy§ } & 7(3.5)\end{array}$

*Some HQ staff have concurrent clinical duties in various clinics. †This includes 54 medical laboratory technicians, 21 radiographers, 10 healthcare attendants.

$\ddagger$ These include regular external contractors who work in SHP premises on daily basis, such as cleaners, security and IT officers and electrical and maintenance workers. This excludes external contractors who visit SHP premises on periodic/scheduled visits. $\S$ Pharmacy sales personnel.

$H Q$, headquarters; SHP, SingHealth Polyclinics.

weight changes. Staff who fail to fit any available respirator masks and/or are pregnant are not deployed to 'red' or 'yellow' zones. Staff undertake refresher courses on the hand hygiene, PPE attire and disposal, via video and in-person demonstrations.

Compliance to infection control practices

Compliance to infection control measures is essential to prevent spread of infection. A DOTF quality assurance 
tracer team was set up in early February 2020 to observe and recommend areas for improvement. Audits on COVID-19 infection prevention are carried out daily by trained staff who observe infection control measure practices and report findings to SHP's Quality Management Department and Infection Prevention and Infectious Diseases Workgroup. Immediate remedial actions are taken. Findings are shared at monthly senior management meetings and disseminated to all polyclinic staff. This was complemented by ad hoc external audits.

\section{Staff work arrangement}

Active monitoring of workforce to ensure adequate frontline staff deployment is necessary to manage the disease outbreak. Cross-institution medical cover is minimised to mitigate any potential spread of infection. Locums are hired to augment medical staff. Each locum is deployed solely to one polyclinic.

The local Ministry of Manpower encouraged back-end staff to 'work from home' where feasible in March 2020, aligned to nationwide measures to reduce community spread of COVID-19. Work from home and split-team arrangements reduce the number of administrative staff and facilitates social distancing in offices. Office access is monitored using a national digital check-in system known as 'Safe Entry'.

In May 2020, Ministry of Health tasked SHP to support medical operations to curb the COVID-19 outbreaks at the migrant worker dormitories. 171 SHP employees volunteered to work in the dormitories, isolation and community care facilities.

Official and leisure overseas travel is suspended for all staff. Staff who return from overseas serve 'Stay Home Notices' at their residences for 14 days. Non-essential leave was cancelled. If leave needs to be taken, staff has to be contactable and return to work, subject to exigencies of service requirements. Staff leave is applied and tracked with the institution's information technology system.

\section{Staff health surveillance}

Health surveillance among staff is critical as they are susceptible to COVID-19 infection. All staff are issued personal thermometers to self-monitor their temperatures twice daily. They submit their temperature readings to the web-based Staff Health Surveillance System via institution computers, laptops or personal smartphones. This enables adherence monitoring and report generation. Supervisors will take action if subordinates default this measure, ranging from reminders to dismissal for repeated lapses.

Staff with fever $\left(\geq 37.5^{\circ} \mathrm{C}\right)$ or acute respiratory illness symptoms are required to seek immediate medical attention at any polyclinic or emergency department at public hospitals. From 23 March 2020, the Infectious Disease Act gazetted 5-day mandatory sick leave for all staff with acute respiratory illness and are disallowed to leave their place of accommodation except to seek medical treatment.
Staff who have been in contact with COVID-19 infected patients are promptly identified by the institution's IT system, electronic medical records and security video cameras at the polyclinics (contact tracing). They are put on active health surveillance for a period of 14 days from the day of contact with the positive case.

\section{Management of infected staff}

Staff with positive COVID-19 swab results are sent to the National Centre for Infectious Disease via dedicated ambulances. They returned to work after recovery at day 28 from the onset of illness. The number of infected staff is tracked.

Contact tracing was similarly conducted in the affected clinics with affected staff on active health surveillance.

\section{Processes}

Screening and controlled entry into the polyclinics

Identifying and segregating COVID-19 suspect cases is introduced early into the pandemic. Each polyclinic had a single point of entry where patients and visitors were segregated and directed to the respective zones. Thermal scanners at screening points help identify febrile patients. All patients and caregivers are screened for acute respiratory illness symptoms and exposure history at the entrance point. Visitor numbers are limited to prevent overcrowding within the polyclinics. Surgical masks are given to patients and caregivers who do not have masks, which also reduces transmission risk to staff.

\section{Social distancing measures within the polyclinics}

The risk of infection of staff increases with the patient load. ${ }^{11}$ Staff proactively identify patients with wellcontrolled non-communicable diseases based on their recent laboratory and clinical records and arrange home delivery to top-up their medication. Increased use of phone and video consults, e-payment, asynchronous referral and appointment scheduling reduced patient contact.

Social distancing between staff is imposed during meals in pantries via alternate seating arrangement. Vinyl barriers are installed on the tables to serve as barriers between staff.

Meetings, trainings and events with large gathering are cancelled or shifted to video-conferencing platforms. Social distancing and wearing of surgical masks are mandated during in-person meetings.

\section{Cleaning and disinfection of premises}

Frequency of cleaning and disinfection of common areas, especially in the 'red' zones are stepped up. High touch points are cleaned up to three times daily with increased frequency of daily checks on toilet cleanliness and waste disposal.

\section{Reduction in academic activities}

Family medicine faculty is deployed to perform clinical duties. Undergraduate, postgraduate, residency training and continuous medical education activities are replaced 
by e-learning programmes and video-conferencing. Research studies and clinical trials involving patient interaction are suspended. Some research staff volunteered to be social distancing ambassadors in the clinics.

Communication and dissemination of outbreak information to staff Updated information is disseminated expeditiously to HCWs pertaining to the evolving outbreak situation so that timely actions are taken to mitigate their infection risks. HCWs receive regular electronic advisories and updates from DOTF and senior management, including evolving relevant outbreak statistics, reminders on infection control measures and social distancing.

\section{Stock check of PPE}

It is critical to ensure adequate supplies of PPE to staff. A periodic automatic replenishment system is used to maintain the stock levels of critical items. The usage of various PPE is tracked daily to ensure timely replenishment of stocks from the central warehouse to each polyclinic.

\section{RESULTS}

During this period, $83.2 \%$ of patients were seen in green zone, $13.8 \%$ in yellow zone and $3.0 \%$ in red zone. A total of 29642 swabs for COVID-19 were performed in SHP. There were $126(0.43 \%)$ positive results including two staff. 395 swabs were carried out in the dormitory and 59 $(14.94 \%)$ were positive.
Only two SHP staff from two different clinics contracted COVID-19. Their sources of infections were not work related. ${ }^{12}$ The affected staff recovered completely and returned to work 28 days later.

The total number of PPE used are shown in table 4 . This includes surgical masks distributed to staff and to patients and/or their accompanying persons who visited SHP.

The PPE in stock is monitored daily. This is illustrated with respirator masks in figure 1. National stockpiles remained sufficient to meet our needs.

The adherence rate of self-declared temperature monitoring by staff is reported in figure 2. Majority of staff reported at least one temperature reading daily. More single temperature readings were reported during weekends. There were 1079 positive readings during this period, with a mean of 6 (range from 0 to 25) per day.

Staff took less leave from February to July 2020, compared with a similar period in the year before. Annual leave was $30.5 \%$ less, and overall leave was $21.2 \%$ less than the preceding year (table 5).

\section{DISCUSSION}

Exposure to COVID-19 infected patients and work overload are two important infective risk factors among HCWs. ${ }^{13}$ Multipronged measures involving timely changes to the policy, infrastructure and processes modification,

Table 4 Utilisation of PPE items and disinfectant items in SHP from February to July 2020

\begin{tabular}{|c|c|c|c|c|c|c|c|c|}
\hline & \multicolumn{3}{|c|}{ Within SHP clinics } & \multicolumn{3}{|c|}{ Outside of SHP clinics } & \multirow[b]{2}{*}{ Total } & \multirow[b]{2}{*}{$\begin{array}{l}\text { Average/ } \\
\text { day* }\end{array}$} \\
\hline & Units & $\begin{array}{l}\text { Clinics } \\
\text { No. of items } \\
(\%)\end{array}$ & $\begin{array}{l}\text { Number } \\
\text { of items/ } \\
\text { suspected } \\
\text { case in } \\
\text { clinics }\end{array}$ & $\begin{array}{l}\text { Dormitory } \\
\text { No. of items } \\
(\%)\end{array}$ & $\begin{array}{l}\text { Swab isolation } \\
\text { facility } \\
\text { No. of items (\%) }\end{array}$ & $\begin{array}{l}\text { HQ } \\
\text { No. of } \\
\text { items (\%) }\end{array}$ & & \\
\hline \multicolumn{9}{|l|}{ PPE item } \\
\hline Face shields & Piece & $987(54)$ & 0.03 & 0 & 0 & $840(46)$ & 1827 & 13.4 \\
\hline Gowns & Piece & $24536(87.4)$ & 0.83 & $2570(9.1)$ & $976(3.5)$ & 0 & 28082 & 206.5 \\
\hline $\begin{array}{l}\text { Respirator } \\
\text { masks }\end{array}$ & Piece & 78937 (94.5) & 2.67 & $1045(1.3)$ & $1874(2.2)$ & $1714(2)$ & 83570 & 614.5 \\
\hline $\begin{array}{l}\text { Disposable shoe } \\
\text { cover }\end{array}$ & Piece & $1600(34)$ & 0.05 & $310(6.6)$ & 2795 (59.4) & 0 & 4705 & 34.6 \\
\hline \multicolumn{9}{|c|}{ Disinfectant items } \\
\hline $\begin{array}{l}\text { Hand rubs/hand } \\
\text { gels }\end{array}$ & $\begin{array}{l}\text { Bottle } \\
(500 \mathrm{~mL})\end{array}$ & $226(68.3)$ & 0.0076 & $23(6.9)$ & $82(24.8)$ & 0 & 331 & 2.4 \\
\hline Wipes & Piece & 31966 (60.5) & 1.08 & 8000 (15.1) & $12900(24.4)$ & 0 & 52866 & 388.7 \\
\hline
\end{tabular}

*In the period February-July 2020, there were 123 weekdays and 26 Saturdays (half-day, except in dormitories).

$\mathrm{HQ}$, headquarters; PPE, personal protection equipment; SHP, SingHealth Polyclinics. 


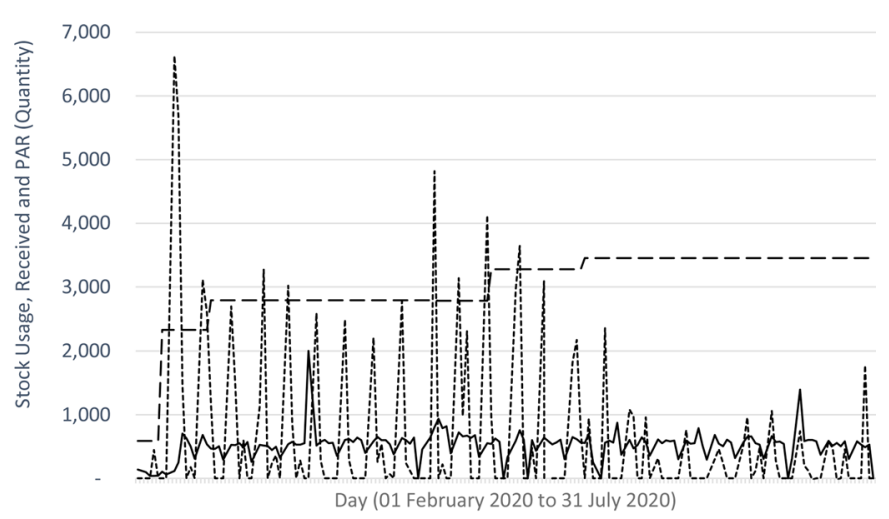

Figure 1 Monitoring of stock usage, stock received and periodic automatic replenishment quantities for respirator masks.

and adherence to the health surveillance of the HCWs are deemed necessary to mitigate their risks.

The availability of appropriate PPE is important in reducing infection. Nguyen $e t a l^{14}$ showed reuse and inadequate PPE by HCWs caring for COVID-19 infected patients had increased risk of being infected themselves compared with those who reported adequate PPE in clinical setting. Adequacy is relative as it is difficult to compare between institutions due to variable local prevalence of COVID-19 infection. For instance, Cattelan $e t$ $a l^{15}$ reported 0.15 gowns, 0.20 respiratory masks and 4.3 gloves used by HCWs per suspected case, while those in SHP used 0.83, 2.67 and 13.17 of the corresponding PPE. A dedicated advance triage area was the setting for the former, in which the number of cases were higher than SHP. In the latter, the PPE utility also varied between the different segregation zones.

Increased workload can lead to fatigue among HCWs and may interfere with their adherence to the infection prevention and control guidelines. ${ }^{16}$ Ran $e t ~ a l^{17}$ alluded to insufficient rest by HCWs in a Wuhan hospital, which contributed to their increased risk COVID-19 infection. In SHP, overall manpower was boosted due to reduced leave applications and overseas leave cancellations. This allows HCWs to receive adequate rest.

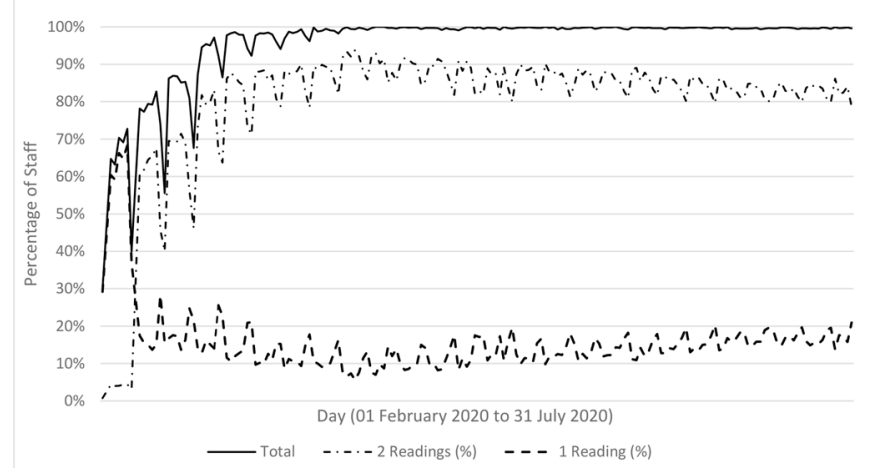

Figure 2 Adherence to daily self-declared temperature monitoring (twice daily).
Table 5 Leave taken by SHP staff from February to July in 2020 and 2019

\begin{tabular}{|c|c|c|c|}
\hline Type of leave & $\begin{array}{l}\text { February- } \\
\text { July } 2020 \\
\text { (days) }\end{array}$ & $\begin{array}{l}\text { February- } \\
\text { July } 2019 \\
\text { (days) }\end{array}$ & $\begin{array}{l}\text { Percentage } \\
\text { change in } \\
2020(\%)\end{array}$ \\
\hline Annual leave & 8066.2 & 11601.0 & -30.5 \\
\hline Sick leave & 7543.6 & 7456.1 & 1.2 \\
\hline $\begin{array}{l}\text { Outpatient sick } \\
\text { leave }\end{array}$ & 3577.4 & 4689.9 & -23.7 \\
\hline $\mathrm{HL}$ & 3966.2 & 2766.2 & $43.4^{*}$ \\
\hline Other leave & 4667.1 & 6675.3 & -30.1 \\
\hline $\begin{array}{l}\text { Family care } \\
\text { leave/childcare } \\
\text { leave }\end{array}$ & 1035.8 & 1345.1 & -23.0 \\
\hline No pay leave & 1173.8 & 1695.6 & -30.8 \\
\hline $\begin{array}{l}\text { Others (eg, } \\
\text { maternity } \\
\text { marriage or } \\
\text { compassionate } \\
\text { leave) }\end{array}$ & 2457.5 & 3634.6 & -32.4 \\
\hline Total leave & 20276.9 & 25732.4 & -21.2 \\
\hline
\end{tabular}

*Increase in HL in 2020 because staff with symptoms of acute respiratory illness were placed on $\mathrm{HL}$ instead of outpatient sick leave (as was done in 2019). There were 2443 days of such HL in 2020.

HL, hospitalisation leave; SHP, SingHealth Polyclinics.

HCWs surveillance allows the institution to identify any emerging internal clusters of infection among staff for rapid intervention. However, time is needed for behaviour modification. Figure 2 illustrates the lag time for HCWs to adhere to the daily temperature monitoring. Soft touch measures by supervisors with frequent nudges and automated reminders via mobile application resulted in improved HCWs' adherence. Activation of disciplinary actions on recalcitrant HCWs was not needed.

HCWs' health-seeking and risk behaviour are critical determinants of their health. The Health Belief Model is a neat framework to encapsulate HCWs' health-seeking behaviour during this pandemic. ${ }^{18-22}$ The policy, infrastructure and processes act synergistically to influence their perceived susceptibility, risks, benefits, address the barriers and provide cues for their actions.

This study reported the multitude of factors associated with the observed minimal infective risks of HCWs in a primary care institution during the pandemic. It is descriptive and observational in nature due to the rapid escalation of the disease outbreak, which necessitates the immediate deployment of measures. During such setting, interventional studies would be deemed inappropriate and unethical.

This descriptive study has limitations. It is challenging to quantify the impact of the measures on the low infectivity rate of healthcare workers and assess the degree of exposure among HCWs. Self-reporting of temperature by staff lacks verification. Staff use a variety of thermometers 
with variable calibration and precision. No standardised staff training on the use of these thermometers was implemented, especially among the non-medical staff.

COVID-19 infection can be asymptomatic. Ideally, all the staff should be swabbed to screen for asymptomatic COVID-19 infections. This was not implemented due to limited swab capacity. Swabs are channelled preferentially for use in COVID-19 infected suspects in the community. Nonetheless, an epidemiology survey using COVID-19 serological testing is currently being conducted to determine the prevalence of subacute infection among HCWs in SHP who may be exposed to the virus in the community.

The authors have adopted a deductive approach in correlating the measures to the outcomes. A more objective evaluation of complex, multifaceted intervention using implementation science will be ideal and should be planned a priori for rapid deployment. Valuable lessons gleamed from this study will be incorporated in the institution pandemic planning to better manage the next emerging infectious disease outbreak.

\section{CONCLUSIONS}

The multipronged intervention involving rapid implementation of novel or modification of public health policies, polyclinic layout, staff training and various infection control measures have largely mitigated the infection risks of primary HCWs in this institution. The COVID-19 pandemic continues to threaten the health and lives of HCWs. Constant review of these measures to determine its relevance and effectiveness is pivotal to keep frontline HCWs safe from the virus, until the widespread uptake of safe and effective vaccines. They are also important when managing future pandemics of similar nature to COVID-19.

Acknowledgements The authors would like to thank the SingHealth Polyclinics directors and colleagues of clinical services, nursing administration, human resource, operations and allied health for retrieving the relevant data. They are also thankful to Caris and Patricia for their assistance in seeking approval from the Institution Review Board.

Contributors All authors made substantial contributions in the planning and execution of various parts of the work. PKSM, ATWA and NCT conceptualised the article and wrote the first draft. MCWN, SSHT and EGT contributed to various parts of the first draft. PKSM, ATWA, NCT and SSHT were involved in the collection, analysis and interpretation of the data. All authors critically reviewed, revised and approved the final manuscript.

Funding The authors have not declared a specific grant for this research from any funding agency in the public, commercial or not-for-profit sectors.

Competing interests None declared.

Patient consent for publication Not required.

Ethics approval SingHealth CIRB E approved exemption of further ethical deliberation for this study on 2 October 2020 (Reference number 2020/2925).

Provenance and peer review Not commissioned; externally peer reviewed.

Data availability statement All data relevant to the study are included in the article.

Open access This is an open access article distributed in accordance with the Creative Commons Attribution Non Commercial (CC BY-NC 4.0) license, which permits others to distribute, remix, adapt, build upon this work non-commercially, and license their derivative works on different terms, provided the original work is properly cited, appropriate credit is given, any changes made indicated, and the use is non-commercial. See: http://creativecommons.org/licenses/by-nc/4.0/.

\section{ORCID iDs}

Peter Kirm Seng Moey http://orcid.org/0000-0003-0483-4427

David Chee Chin Ng http://orcid.org/0000-0001-8887-0956

Ngiap Chuan Tan http://orcid.org/0000-0002-5946-1149

\section{REFERENCES}

1 Ministry of Health, Singapore. Five more cases discharged; 74 new cases of COVID-19 infection confirmed. Moh.gov.sg, updates on COVID-19 local situation, 2020.

2 Ministry of Health, Singapore. Daily report on COVID-19, 2020.

3 Wong LY, Tan AL, Leo Yee-Sin, et al. Healthcare workers in Singapore infected with COVID-19: 23 January-17 April 2020. Influenza Other Respi Viruses 2021;15:218-26.

4 World Health Organization (WHO). Coronavirus disease 2019 (COVID-19). situation report - 82, 2020.

5 Wu Z, McGoogan JM. Characteristics of and important lessons from the coronavirus disease 2019 (COVID-19) outbreak in China. JAMA 2020;323:1239-42.

6 Burrer SL, de Perio MA, Hughes MM, et al. Characteristics of Health Care Personnel with COVID-19 - United States, February 12-April 9, 2020. MMWR Morb Mortal Wkly Rep 2020;69:477-81. 15.

7 SHP. Available: https://polyclinic.singhealth.com.sg/aboutsinghealth-polyclinics mean [Accessed 13 May 2020].

8 What do the different DORSCON levels mean. Available: https:// www.gov.sg/article/what-do-the-different-dorscon-levels-mean [Accessed 13 May 2020].

9 Ending circuit breaker: phased approach to resuming activities safely, 2020. Available: www.gov.sg [Accessed July 2020].

10 Moving into phase 2: what activities can resume, 2020. Available: www.gov.sg [Accessed Nov 2020].

11 Scientific brief: SARS-CoV-2 transmission. Available: https://www. cdc.gov/coronavirus/2019-ncov/science/science-briefs/sars-cov-2transmission.html\#anchor_1619805167515 [Accessed May 2021].

12 Kurohi R. 66 healthcare workers infected but none likely in the course of work. The Straits Times, 2020. Available: https://www.straitstimes. $\mathrm{com} /$ politics/66-healthcare-workers-infected-but-none-likely-in-thecourse-of-work [Accessed 15 March 2021]

13 Mhango M, Dzobo M, Chitungo I, et al. COVID-19 risk factors among health workers: a rapid review. Saf Health Work 2020;11:262-5.

14 Nguyen LH, Drew DA, Graham MS, et al. Risk of COVID-19 among front-line health-care workers and the general community: a prospective cohort study. Lancet Public Health 2020;5:e475-83.

15 Cattelan AM, Sasset L, Di Meco E, et al. An integrated strategy for the prevention of SARS-CoV-2 infection in healthcare workers: a prospective observational study. Int J Environ Res Public Health 2020;17:5785.

16 Houghton C, Meskell P, Delaney $\mathrm{H}$, et al. Barriers and facilitators to healthcare workers' adherence with infection prevention and control (IPC) guidelines for respiratory infectious diseases: a rapid qualitative evidence synthesis. Cochrane Database Syst Rev 2020;4:CD013582.

17 Ran L, Chen X, Wang Y, et al. Risk factors of healthcare workers with coronavirus disease 2019: a retrospective cohort study in a designated hospital of Wuhan in China. Clin Infect Dis 2020;71:2218-21.

18 Rosenstock IM. Historical origins of the health belief model. Health Educ Monogr 1974;2:328-35.

19 Janz NK, Becker MH. The health belief model: a decade later. Health Educ Q 1984;11:1-47.

20 Costa MF. Health belief model for coronavirus infection risk determinants. Rev Saude Publica 2020;54:47.

21 Eichenberg C, Grossfurthner M, Andrich J, et al. The relationship between the implementation of statutory preventative measures, perceived susceptibility of COVID-19, and personality traits in the initial stage of Corona-Related Lockdown: a German and Austrian population online survey. Front Psychiatry 2021;12:596281.

$22 \mathrm{Kim} \mathrm{S}$, Kim S. Analysis of the impact of health beliefs and resource factors on preventive behaviors against the COVID-19 pandemic. Int $J$ Environ Res Public Health 2020;17:8666. 